\title{
Infiltration and Adsorption of Dissolved Atrazine and Atrazine Metabolites in Buffalograss Filter Strips
}

\author{
L. J. Krutz,* S. A. Senseman, M. C. Dozier, D. W. Hoffman, and D. P. Tierney
}

\begin{abstract}
Vegetated filter strips (VFS) potentially reduce the off-site movement of herbicides from adjacent agricultural fields by increasing herbicide mass infiltrated $\left(M_{\text {inf }}\right)$ and mass adsorbed $\left(M_{\mathrm{as}}\right)$ compared with bare field soil. However, there are conflicting reports in the literature concerning the contribution of $M_{\text {as }}$ to the VFS herbicide trapping efficiency (TE). Moreover, no study has evaluated TE among atrazine (6-chloro- $N$-ethyl- $N^{\prime}$-isopropyl-[1,3,5] triazine-2,4-diamine) and atrazine metabolites. This study was conducted to compare TE, $M_{\text {inf }}$, and $M_{\text {as }}$ among atrazine, diaminoatrazine (DA, 6-chloro$[1,3,5]$ triazine-2,4-diamine), deisopropylatrazine (DIA, 6-chloro- $N$ ethyl-[1,3,5]triazine-2,4-diamine), desethylatrazine (DEA, 6-chloro$\mathrm{N}$-isopropyl-[1,3,5]triazine-2,4-diamine), and hydroxyatrazine (HA, 6-hydroxy- $N$-ethyl- $N$ '-isopropyl-[1,3,5] triazine-2,4-diamine) in a buffalograss VFS. Runoff was applied as a point source upslope of a 1- $\times$ 3-m microwatershed plot at a rate of $750 \mathrm{~L} \mathrm{~h}^{-1}$. The point source was fortified at $0.1 \mu \mathrm{g} \mathrm{mL}^{-1}$ atrazine, DA, DIA, DEA, and HA. After crossing the length of the plot, water samples were collected at 5-min intervals. Water samples were extracted by solid phase extraction and analyzed by high performance liquid chromatography (HPLC) photodiode array detection. During the 60 -min simulation, TE was significantly greater for atrazine $\mathbf{( 2 2 . 2} \%)$ compared with atrazine metabolites (19.0\%). Approximately 67 and $33 \%$ of the TE was attributed to $M_{\text {inf }}$ and $M_{\text {as }}$, respectively. These results demonstrate that herbicide adsorption to the VFS grass, grass thatch, and/or soil surface is an important retention mechanism, especially under saturated conditions. Values for $\boldsymbol{M}_{\text {as }}$ were significantly higher for atrazine compared with atrazine's metabolites. The $M_{\text {as }}$ data indicate that atrazine was preferentially retained by the VFS grass, grass thatch, and/or soil surface compared with atrazine's metabolites.
\end{abstract}

$\mathrm{R}$ UNOFF WATER can transport field-applied herbicides and herbicide metabolites to surface water bodies including rivers, lakes, and streams, resulting in deterioration of surface water quality. Extensive research has been conducted regarding the occurrence and environmental fate of herbicides in the hydrologic system. Few studies have considered herbicide metabolites. However, both herbicides and their metabolites have been detected in surface and ground water (Senseman et al., 1997; Lerch et al., 1998; Kolpin et al., 2000; Lambropoulou et al., 2002). Moreover, herbicide metabolites frequently constitute a majority of the concentration mea-

L.J. Krutz and S.A. Senseman, Dep. of Soil and Crop Sci., Texas Agric. Exp. Stn., Texas A\&M Univ., and M.C. Dozier, Dep. of Soil and Crop Sci., Texas Cooperative Extension, Texas A\&M Univ., College Station, TX 77843; D.W. Hoffman, Blackland Res. Center, Texas Agric. Exp. Stn., Temple, TX; D.P. Tierney, Environ. Stewardship and Regulatory Policy, Syngenta Crop Protection, P.O. Box 18300, Greensboro, NC. Received 24 Jan. 2003. *Corresponding author (lkrutz@ag.tamu.edu).

Published in J. Environ. Qual. 32:2319-2324 (2003).

(c) ASA, CSSA, SSSA

677 S. Segoe Rd., Madison, WI 53711 USA sured in both surface and ground water (Kolpin et al., 1996, 2000; Thurman et al., 1996).

Vegetated filter strips are narrow strips of permanent vegetation that potentially reduce the off-site movement of herbicides from adjacent agricultural fields (Webster and Shaw, 1996). Data indicate that greater infiltration in VFS compared with bare field soil is the governing process for the retention of moderately adsorbed herbicides (Arora et al., 1996; Misra et al., 1996; Kloppel et al., 1997; Barfield et al., 1998; Schmitt et al., 1999; Seybold et al., 2001). However, herbicide adsorption to the VFS grass, grass thatch, and/or soil surface is also a proposed retention mechanism.

There are conflicting reports concerning the contribution of herbicide adsorption to VFS grass, grass thatch, and/or soil surfaces to TE. Kloppel et al. (1997) reported that sorption to VFS grass, grass thatch, and/or soil surfaces did not significantly contribute to the retention of the highly soluble dichlorprop-p and the moderately soluble terbuthylazine. Conversely, others have inferred that herbicide adsorption to grass thatch and soil surfaces is an important VFS retention mechanism (Briggs et al., 1999; Misra et al., 1996; Seybold et al., 2001).

Adsorption differences between atrazine and atrazine metabolite have been reported for various soils. Generally, adsorption decreases in the order of HA > atrazine $>$ DIA $>$ DEA (Brouwer et al., 1990; Mersie and Seybold, 1996; Seybold and Mersie, 1996). Soil adsorption data indicate the potential for retention differences among atrazine and atrazine metabolites in VFS. However, atrazine and atrazine metabolites retention in VFS has not been evaluated. Therefore, a project was designed to compare TE, mass infiltrated $\left(M_{\text {inf }}\right)$, and mass adsorbed $\left(M_{\mathrm{as}}\right)$ among atrazine and four atrazine metabolites including DA, DIA, DEA, and HA applied simultaneously to a buffalograss VFS.

\section{MATERIALS AND METHODS}

\section{Materials}

All compounds were supplied by Syngenta Crop Protection (Greensboro, NC). The purity for analytical grade atrazine, DA, DIA, DEA, and HA was 98, 97, 96, 94, and 97\%, respectively.

\section{Simulated Run-On Description}

Run-on simulations were conducted in June 2001 and June 2002 at the Blackland Research Center in Temple, TX. The soil type was a Houston Black clay (very-fine, smectitic, thermic Oxyaquic Hapluderts) with an average slope of $2 \%$. Buffa-

Abbreviations: DA, diaminoatrazine; DEA, desethylatrazine; DIA, deisopropylatrazine; HA, hydroxyatrazine; HPLC, high performance liquid chromatography; TE, trapping efficiency; VFS, vegetated filter strips. 
lograss $\{$ Buchloe dactyloides (Nutt.) Engelm. [= Bouteloua dactyloides (Nutt.) Columbus]\} plots, 1 by $3 \mathrm{~m}$, were constructed by erecting $15-\mathrm{cm}$ high metal strips along the length of the plot with a metal catchment device installed on the down-slope end.

Simulated runoff was created in an $813-\mathrm{L}$ polyethylene nurse tank and fortified at $0.1 \mu \mathrm{g} \mathrm{mL} \mathrm{m}^{-1}$ atrazine, DA, DIA, DEA, and HA. Before adding the compounds to the nurse tank, atrazine, DA, DIA, and DEA were dissolved in $350 \mathrm{~mL}$ of methanol $(\mathrm{MeOH})$, and HA was dissolved in $150 \mathrm{~mL}$ of water, $\mathrm{MeOH}$, and formic acid (74.5:25:0.5 v/v). This step was required to ensure that all compounds were in the dissolved phase.

Atrazine concentrations were based on prior runoff field studies (Hoffman et al., 2002). Similar data were not available for atrazine's metabolites. Researchers have reported that relative TE depends on nominal inflow concentration (Misra et al., 1996; Kloppel et al., 1997). These data indicated that atrazine and atrazine metabolite nominal inflow concentrations must be equal to compare relative TE among compounds.

To ensure a conservative TE estimate (Barfield et al., 1998), the VFS was saturated with sprinklers to the point that surface runoff was generated. Before applying runoff from the nurse tank, the plots were allowed to drain for $10 \mathrm{~min}$. Runoff containing atrazine and all atrazine metabolites was applied as sheet flow to a given plot at a rate of $750 \mathrm{~L} \mathrm{~h}^{-1}$ (Wolfe et al., 2000). The run-on simulation rate was based on the runoff amount expected from a 51-mm rainfall intercepted by a $30-$ m-long field directly up-slope of the strip (Wolfe et al., 2000). Runoff was collected in the catchment device and transferred to a holding tank with a $1.7 \times 10^{-3} \mathrm{~Pa}$ pressure transducer. The runoff rate was determined by recording the water height with an electronic data logger at 3-s intervals. One litter of runoff was collected from the outflow in 1-L glass amber jars at 5-min intervals during the 60 -min simulation and stored at $4^{\circ} \mathrm{C}$ until analysis. A total of 12 runoff samples were collected from each plot during the simulation.

\section{Extraction Method}

Before extraction, an internal standard (metolachlor) was added to $250-\mathrm{mL}$ water samples. The samples were passed through a solid phase extraction ENVI-carb (Supelco, Bellefonte, PA) cartridge containing $0.25 \mathrm{~g}$ of graphitized carbon black. The cartridge was cleaned, conditioned, and eluted as described by Panshin et al. (2001). The elution was dried under a stream of $\mathrm{N}$ and brought to $2 \mathrm{~mL}$ with acetonitrile.

\section{High Performance Liquid Chromatography Analysis}

Samples were analyzed on a Waters RP8 symmetry shield C8 column with a Waters HPLC instrument equipped with a photodiode array detector (Waters Inc., Milford, MA) set at the $225-\mathrm{nm}$ wavelength. The injection volume was $20 \mu \mathrm{L}$, and

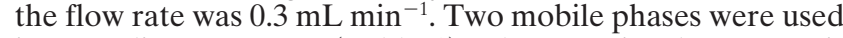
in a gradient program (Table 1). They consisted of acetoni-

Table 1. High performance liquid chromatography mobile phase gradient profile for atrazine and atrazine metabolite separation. Initial and final mobile phases were acetonitrile-water-0.07 $M$ ammonium acetate buffer (10:75:15 v/v) and acetonitrilewater-0.07 $M$ ammonium acetate buffer $(80: 5: 15 \mathrm{v} / \mathrm{v})$, respectively.

\begin{tabular}{lcr}
\hline Time & Initial mobile phase & Final mobile phase \\
\cline { 2 - 3 } min & & \\
0 & 100 & 0 \\
5 & 100 & 0 \\
6 & 0 & 100 \\
26 & 0 & 100 \\
27 & 100 & 0 \\
\hline
\end{tabular}

trile-water-0.07 $M$ ammonium acetate buffer (10:75:15 v/v) and acetonitrile-water-0.07 $M$ ammonium acetate buffer $(80: 5: 15 \mathrm{v} / \mathrm{v})$ for the initial and final mobile phases, respectively.

\section{Quality Assurance Data}

Quality assurance data for each run-on simulation included a lab-blank, lab-fortified, tank-blank, field-blank, and tankfortified sample. Contamination that might have occurred during sample processing was assessed with the lab-blank (deionized water) data, and percentage recovery was calculated from lab-fortified samples. Tank blanks consisted of samples collected from the application nurse tank before fortification with the herbicide and metabolites to ensure that no carryover from previous treatments was introduced into a new plot. Field blanks consisted of samples collected from the catchment device before fortification of the nurse tank to ensure that the plot area was void of contamination with the herbicide and metabolites. After fortification of the nurse tank, tankfortified samples were collected to ensure that the atrazine and atrazine metabolite concentrations were approximately $0.1 \mu \mathrm{g} \mathrm{mL} \mathrm{mL}^{-1}$. The method's limit of detection, limit of quantitation, and percentage recovery are reported in Table 2 .

\section{Mass Balance Determination}

The VFS ability to retain atrazine and atrazine metabolites was evaluated by determining TE as described by Barfield et al. (1998):

$$
\mathrm{TE}=\left(M_{\mathrm{i}}-M_{\mathrm{o}}\right) / M_{\mathrm{i}}
$$

where $M_{\mathrm{i}}$ represents the total herbicide mass flowing onto the VFS, and $M_{\mathrm{o}}$ represents the total herbicide mass flowing off the VFS. $M_{\mathrm{i}}$ and $M_{\mathrm{o}}$ were calculated from Eq. [2] and [3], respectively:

$$
\begin{aligned}
& M_{\mathrm{i}}=\Sigma q_{\mathrm{i}} C_{\mathrm{i}} d t \text { and } \\
& M_{\mathrm{o}}=\Sigma q_{\mathrm{o}} C_{\mathrm{o}} d t
\end{aligned}
$$

where $q_{\mathrm{i}}$ and $q_{\mathrm{o}}$ were runoff inflow and outflow rates, $C_{\mathrm{i}}$ and $C_{\text {o }}$ were runoff inflow and outflow herbicide concentrations, and $t$ was the time required to perform the simulation.

A mass balance for the VFS system was constructed as described in Eq. [4]:

$$
M_{\mathrm{i}}-M_{\mathrm{o}}=M_{\mathrm{inf}}+M_{\mathrm{as}}
$$

where $M_{\text {inf }}$ represents the herbicide mass infiltrated during the simulation, and $M_{\text {as }}$ represents the herbicide mass adsorbed to the VFS grass, grass thatch, and/or soil surface. $M_{\text {inf }}$ was calculated as described in Eq. [5] assuming that the volume infiltrated $\left(V_{\text {inf }}\right)$ was the difference between runoff inflow and outflow volume:

$$
M_{\text {inf }}=V_{\text {inf }} C_{\text {avg }}
$$

where $C_{\text {avg }}$ is the average herbicide concentration that moved across the filter strip during the simulation

Table 2. Percentage recovery, retention time, method limit of detection (LOD), and method limit of quantitation (LOQ) for five herbicides.

\begin{tabular}{lcccc}
\hline Compound & Retention Time & Recovery & LOD & LOQ \\
\hline & $\min$ & $\%$ & $-\mu \mathrm{L}^{-1}-$ \\
Atrazine & $\mathbf{1 7 . 5 2}$ & $\mathbf{9 9} \pm \mathbf{2}$ & $\mathbf{1 . 2 8}$ & $\mathbf{1 3 . 0}$ \\
Diaminoatrazine & $\mathbf{3 . 7 8}$ & $\mathbf{9 8} \pm 4$ & $\mathbf{1 . 3 0}$ & $\mathbf{1 3 . 0}$ \\
Deisopropylatrazine & $\mathbf{1 0 . 7 6}$ & $\mathbf{9 9} \pm \mathbf{2}$ & $\mathbf{1 . 6 0}$ & $\mathbf{1 6 . 0}$ \\
Desethylatrazine & $\mathbf{1 6 . 0 3}$ & $\mathbf{9 7} \pm 4$ & $\mathbf{4 . 6 0}$ & $\mathbf{4 6 . 0}$ \\
Hydroxyatrazine & $\mathbf{1 5 . 7 7}$ & $\mathbf{9 0} \pm \mathbf{8}$ & $\mathbf{2 . 3 0}$ & $\mathbf{1 3 . 0}$ \\
\hline
\end{tabular}




$$
C_{\text {avg }}=\left(C_{\text {iavg }}+C_{\text {oavg }}\right) / 2
$$

where $C_{\text {iavg }}$ was the average inflow herbicide concentration and $C_{\text {oavg }}$ was the average outflow herbicide concentration. $M_{\text {as }}$ was calculated by manipulating the mass balance equation as described in Eq. [7]:

$$
M_{\text {as }}=M_{\mathrm{i}}-M_{\mathrm{o}}-M_{\mathrm{inf}}
$$

\section{Statistical Analysis}

The study design for both years was a randomized complete block with four replications. Data were analyzed for heterogenous error variances between years and then pooled. Treatment means for TE, $M_{\text {inf }}$, and $M_{\text {as }}$ were subjected to analysis of variance and separated by Fisher's LSD. Relationships between variables were evaluated with linear regression.

\section{RESULTS AND DISCUSSION}

Atrazine and atrazine metabolite TE was calculated from Eq. [1] and represents the combined effects of $M_{\text {inf }}$ and $M_{\text {as }}$ on the total herbicide load retained by the VFS. Trapping efficiency was greater for atrazine compared with atrazine metabolites (Fig. 1). A similar trend has been reported for metolachlor and two metolachlor metabolites including metolachlor oxanilic acid and metolachlor ethanesulfonic acid in buffalograss filter strips (Krutz et al., 2002). Differences in TE between the parent compound and the metabolites are likely associated with a greater tendency for the parent compounds to be retained as $M_{\text {as }}$ (Krutz et al., 2002).

Atrazine and atrazine metabolite TE was considerably less than results reported from natural rainfall (Arora et al., 1996; Lowrance et al., 1997; Patty et al., 1997; Vellidis et al., 2002), simulated rainfall (Asmussen et al., 1977; Rhode et al., 1980; Barfield et al., 1998), and simulated run-on experiments (Misra et al., 1996; Kloppel et al., 1997; Mersie et al., 1999; Schmitt et al., 1999; Seybold et al., 2001). In natural rainfall studies, atrazine TE was relatively high: 11 to $100 \%$ (Arora et al., 1996), 97\% (Lowrance et al., 1997), 44 to 97\% (Patty et al., 1997), and 97\% (Vellidis et al., 2002). Similar trends are reported for two atrazine metabolites including DEA and DIA with TE of 55 to $98 \%$ and 45 to $97 \%$, respectively (Patty et al., 1997). In a simulated rainfall experiment, Barfield et al. (1998) reported that atrazine loads exiting the VFS were reduced by $90 \%$ compared with the inflow atrazine load. Analogous trends are reported for simulated run-on studies where atrazine TE was 29\% (Misra et al., 1996), 44\% (Misra et al. 1996), 52\% (Mersie et al., 1999), and 53\% (Seybold et al., 2001).

The lower atrazine and atrazine metabolite TE in this study compared with published data is likely associated with differences in factors among studies that affect $M_{\text {inf }}$, including VFS width and moisture content. In this study the VFS width was only $3 \mathrm{~m}$. A wide variety of VFS widths have been evaluated in the literature with most being $>3 \mathrm{~m}$. These various widths include the following: $2.0 \mathrm{~m}$ (Mersie et al., 1999; Seybold et al., 2001), $4.6 \mathrm{~m}$ (Barfield et al., 1998), $5.7 \mathrm{~m}$ (Patty et al., 1997), $9.1 \mathrm{~m}$ (Barfield et al., 1998), $10 \mathrm{~m}$ (Kloppel et al., 1997), $11.1 \mathrm{~m}$ (Patty et al., 1997), $12.2 \mathrm{~m}$ (Misra et al., 1996) $13.7 \mathrm{~m}$ (Barfield et al., 1998), and $20.1 \mathrm{~m}$ (Arora et al., 1996). In studies that have evaluated the effect of VFS width on herbicide TE, all but one research group (Tingle et al., 1998) reported that TE was positively correlated with VFS width (Lowrance et al., 1997; Patty et al., 1997;

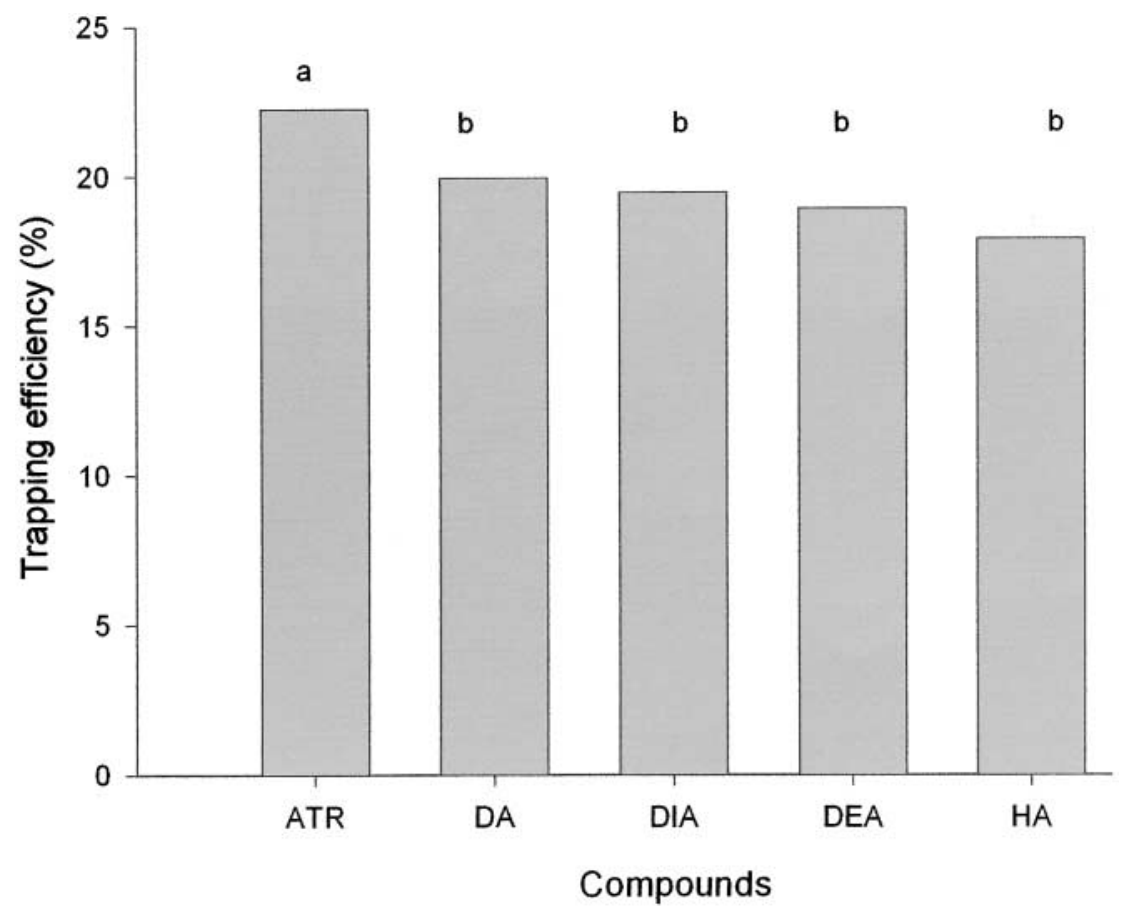

Fig. 1. The mean trapping efficiency for atrazine (ATR), diaminoatrazine (DA), deisopropylatrazine (DIA), desethylatrazine (DEA), and hydroxyatrazine (HA) during the 60-min run-on simulation. Values presented for each compound are the mean of eight replications. Compounds followed by the same letter are not significantly different at $\boldsymbol{P} \leq \mathbf{0 . 0 6}$. 


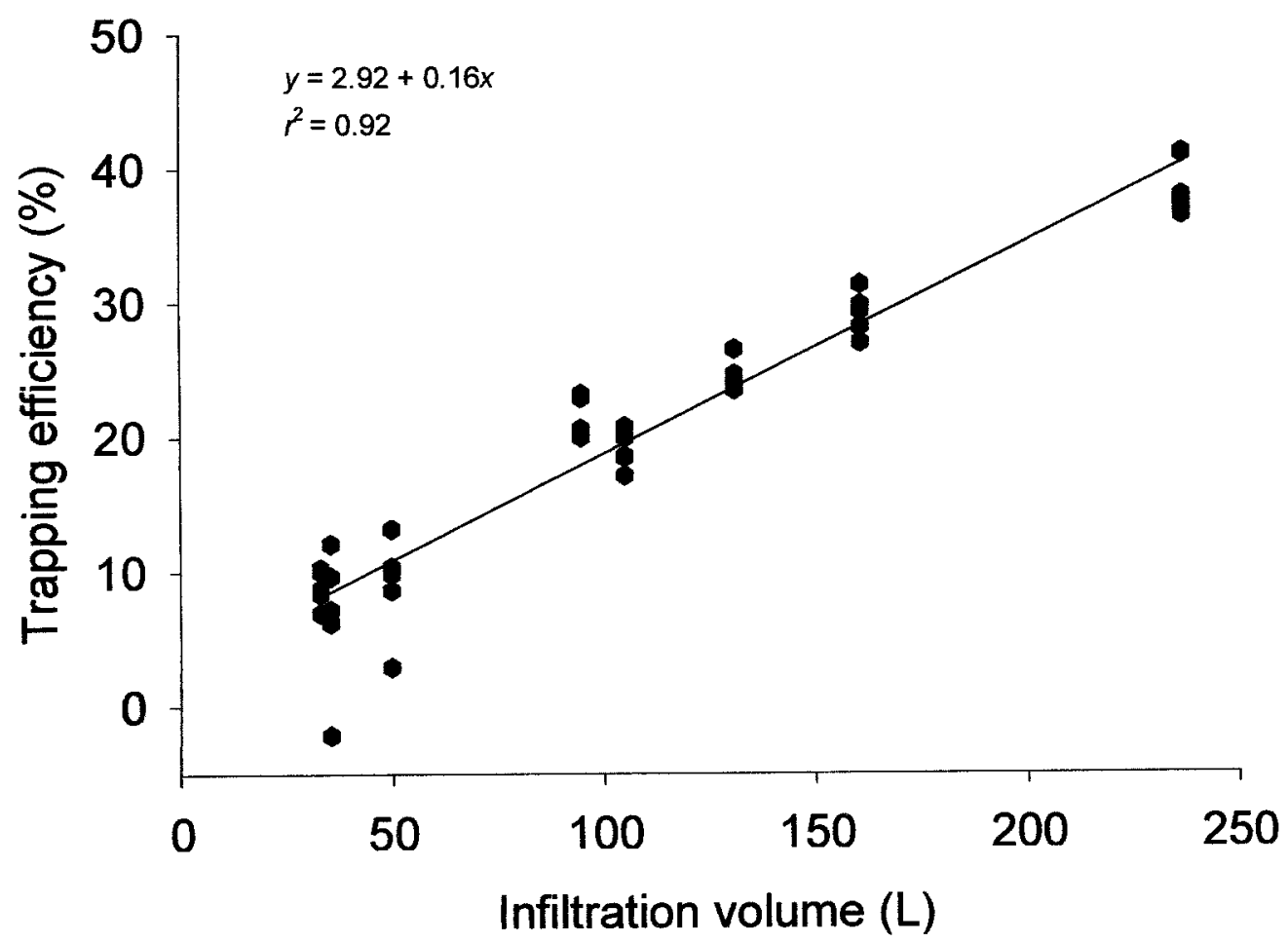

Fig. 2. Relationship between trapping efficiency and infiltration volume for each replication and compound during the 2-yr run-on simulation study.

Barfield et al., 1998; Schmitt et al., 1999; Vellidis et al., 2002). Moreover, data indicate that $M_{\text {inf }}$ is inversely correlated with VFS antecedent moisture content (Asmussen et al., 1977; Rhode et al., 1980; Arora et al., 1996). In this study, the 3-m VFS was saturated before application of the simulated runoff, thus lowering the potential for $M_{\text {inf. }}$. However, even under saturated conditions, considerable atrazine and atrazine metabolites were retained as $M_{\text {inf }}$.

The average $M_{\text {inf }}$ for atrazine and atrazine metabolites was $13.5 \pm 0.2 \%$ and accounted for approximately $64 \%$ of the total TE for these compounds. Moreover, there was a significant linear relationship between TE and $V_{\text {inf }}$ indicating that infiltration is a key retention mechanism for atrazine and atrazine metabolites (Fig. 2). Others have reported that infiltration is the primary atrazine retention mechanism by VFS (Arora et al., 1996; Misra et al., 1996; Kloppel et al., 1997; Barfield et al., 1998; Schmitt et al., 1999; Seybold et al., 2001).

The most controversial aspect of herbicide retention by VFS is adsorption to grass thatch and soil surfaces. Several researchers have reported reduced herbicide concentrations at the VFS outflow compared with VFS inflow. This reduction in herbicide concentration has been attributed to both dilution (Kloppel et al., 1997; Schmitt et al., 1999) and adsorption to the VFS grass, grass thatch, and/or the soil surface (Asmussen et al., 1977; Misra et al., 1996; Lowrance et al., 1997; Briggs et al., 1999; Vellidis et al., 2002). Researchers agree that dilution resulting from rainwater falling on the VFS surface and mixing with runoff contributes to herbicide concentration reductions between VFS inflow and VFS outflow (Kloppel et al., 1997). However, there are con- flicting reports in the literature regarding the contribution of $M_{\text {as }}$ to TE.

In this study, $M_{\text {as }}$ was significantly different between atrazine and atrazine metabolites $(P=0.004)$ (Fig. 3). $M_{\text {as }}$ accounted for approximately 40 and $26 \%$ of the atrazine and atrazine metabolite TE, respectively. The $M_{\text {as }}$ data indicate that concentration changes between VFS inflow and VFS outflow are associated with an adsorption mechanism. Although herbicide adsorption to the VFS grass, grass thatch, and/or soil surface has been proposed by several authors (Asmussen et al., 1977; Misra et al., 1996; Lowrance et al., 1997; Briggs et al., 1999; Vellidis et al., 2002), few have attempted to quantify the contribution of $M_{\text {as }}$ to herbicide TE. An exception is the work of Barfield et al. (1998) who reported that $M_{\text {as }}$ significantly contributed to herbicide TE. Moreover, they reported a direct correlation between $M_{\text {as }}$ and VFS width. They concluded that the opportunity for chemical adsorption by atrazine to the VFS grass, grass thatch, and/or soil surface increased as VFS width increased. These data imply that the relatively low TE for atrazine and atrazine metabolites reported in this paper may be increased by implementing wider filter strips.

The comparison of $M_{\mathrm{as}}$ among atrazine and atrazine metabolites indicates that the buffalograss VFS preferentially retained atrazine over atrazine metabolites. Retention differences among compounds may be related to hydrophobic interactions among the compounds and the VFS grass, grass thatch, and or soil surface. For example, retention of atrazine to the reverse-phase (octyl, $\mathrm{C}_{8}$ ) HPLC column used for separation in this experiment was greater than the retention of the atrazine 


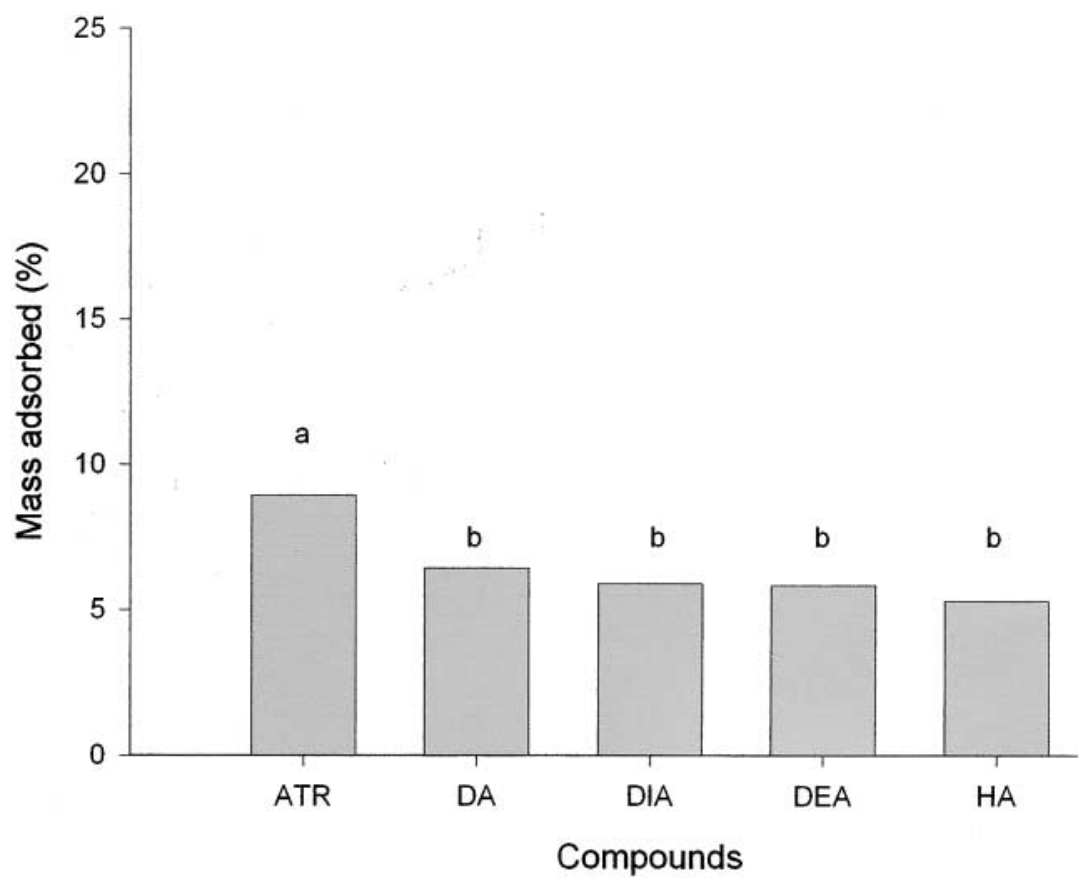

Fig. 3. Mean mass adsorbed for atrazine (ATR), diaminoatrazine (DA), deisopropylatrazine (DIA), desethylatrazine (DEA), and hydroxyatrazine (HA) during the 60-min run-on simulation. Values presented for each compound are the mean of eight replications. Compounds followed by the same letter are not significantly different at $P \leq 0.05$.

metabolites (Table 2). Moreover, atrazine and atrazine metabolite retention to the $\mathrm{C}_{8}-$ HPLC column followed the hydrophobicity of the compounds. These results suggest that retention differences among atrazine and atrazine metabolites may be associated with hydrophobic interactions among the compounds VFS grass, grass thatch, and or soil surface. A similar trend has been reported for metolachlor, metolachlor oxanilic acid, and metolachlor ethanesulfonic acid in buffalograss filter strips (Krutz et al., 2002). Future studies should be designed to better assess the validity of this relationship.

\section{CONCLUSIONS}

The buffalograss filter strip retained approximately $22 \%$ of the incoming dissolved atrazine load compared with $19.0 \%$ of the dissolved atrazine metabolite load during the 60-min simulation. Approximately 67 and $33 \%$ of the TE was attributed to mass infiltrated and mass adsorbed, respectively. These results demonstrate that herbicide adsorption to the VFS grass, grass thatch, and/or soil surface is an important retention mechanism, especially under saturated conditions. Moreover, mass adsorbed was significantly greater for atrazine compared with atrazine's metabolites. These results indicate that the atrazine metabolites including DA, DIA, DEA, and HA are not as readily retained by VFS grass, grass thatch, and/or soil surfaces as the parent compound. Retention differences among compounds may be associated with hydrophobic interactions among the compounds and the vegetative filter strip's grass, grass thatch, and or soil surface.

\section{REFERENCES}

Arora, K., S.K. Mickelson, J.L. Baker, D.P. Tierney, and C.J. Peters. 1996. Herbicide retention by vegetative buffer strips from runoff under natural rainfall. Trans. ASAE 39:2155-2162.

Asmussen, L.E., A.W. White, Jr., E.W. Hauser, and J.M. Sheridan. 1977. Reduction of 2,4-D load in surface runoff down a grassed waterway. J. Environ. Qual. 6:159-162.

Barfield, B.J., R.L. Blevins, A.W. Fogle, C.E. Madison, S. Inamdar, D.I. Carey, and V.P. Evangelou. 1998. Water quality impacts of natural filter strips in karst areas. Trans. ASAE 41:371-381.

Briggs, J.A., T. Whitwell, and M.B. Riley. 1999. Remediation of herbicides in runoff water from container plant nurseries utilizing grassed waterways. Weed Technol. 13:157-164.

Brouwer, W.W.M., J.J.T. Boesten, and W.G. Siegers. 1990. Adsorption of transformation products of atrazine by soil. Weed Res. 30: 123-128.

Hoffman, D., S. Senseman, and M. Dozier. 2002. Blackland prairie demonstration program: Use of contour grass filter strips to reduce non-point source herbicide and sediment losses. BRC Rep. no. $02-$ 10. Texas Agric. Exp. Stn., College Station.

Kloppel, H., W. Kordel, and B. Stein. 1997. Herbicide transport by surface runoff and herbicide retention in a filter strip-Rainfall and runoff simulation studies. Chemosphere 35:129-141.

Kolpin, D.W., E.M. Thurman, and D.A. Goolsby. 1996. Occurrence of selected pesticides and their metabolites in near-surface aquifers of the Midwestern United States. Environ. Sci. Technol. 30: 335-340.

Kolpin, D.W., E.M. Thurman, and S.M. Linhart. 2000. Finding minimal herbicide concentrations in ground water? Try looking for their degradates. Sci. Total Environ. 248:115-122.

Krutz, L.J., S.A. Senseman, M.C. Dozier, D.W. Hoffman, and D.P. Tierney. 2002. Effectiveness of buffalograss (Buchloe dactyloides Nutt. Engelm) filter strips in removing dissolved metolachlor and metolachlor metabolites from surface runoff. Proc. South. Weed Sci. Soc. 55:153.

Lambropoulou, D.A., V.A. Sakkas, D.G. Hela, and T.A. Albanis. 2002. Application of solid-phase microextraction in the monitoring of priority pesticides in the Kalmas river (N.W. Greece). J. Chromatogr., A. 963:107-116.

Lerch, R.N., P.E. Blanchard, and E.M. Thurman. 1998. Contribution 
of hydroxylated atrazine degradation products to the total atrazine load in Midwestern streams. Environ. Sci. Technol. 32:40-48.

Lowrance, R., G. Vellidis, R.D. Wauchope, P. Gay, and D.D. Bosch. 1997. Herbicide transport in a managed riparian forest buffer system. Trans. ASAE 40:1047-1057.

Mersie, W., and C. Seybold. 1996. Adsorption and desorption of atrazine, deethylatrazine, deisopropylatrazine, and hydroxyatrazine on levy wetland soil. J. Agric. Food Chem. 44:1925-1929.

Mersie, W., C.A. Seybold, C. McNamee, and J. Huang. 1999. Effectiveness of switchgrass filter strips in removing dissolved atrazine and metolachlor from runoff. J. Environ. Qual. 28:816-821.

Misra, A.K., J.L. Baker, S.K. Mickelson, and H. Sang. 1996. Contributing area and concentration effects on herbicide removal by vegetative buffer strips. Trans. ASAE 39:2105-2111.

Panshin, S.Y., D.S. Carter, and E.R. Bayless. 2001. Analysis of atrazine and four degradation products in the pore water of the vadose zone, central Indiana. Environ. Sci. Technol. 34:2131-2137.

Patty, L., B. Real, and J.J. Gril. 1997. The use of grassed buffer strips to remove pesticides, nitrate and soluble phosphorus compounds from runoff water. Pestic. Sci. 49:243-251.

Rhode, W.A., L.E. Asmussen, E.W. Hauser, R.D. Wauchope, and H.D. Allison. 1980. Trifluralin movement in runoff from a small agricultural watershed. J. Environ. Qual. 9:37-42.

Schmitt, T.J., M.G. Dosskey, and K.D. Hoagland. 1999. Filter strip performance and processes for different vegetation, widths, and contaminants. J. Environ. Qual. 28:1479-1489.
Senseman, S.A., T.L. Lavy, and T.C. Daniel. 1997. Monitoring groundwater for pesticides at selected mining/loading sites in Arkansas. Environ. Sci. Technol. 31:283-288.

Seybold, C.A., and W. Mersie. 1996. Adsorption and desorption of atrazine, deethylatrazine, deisopropylatrazine, hydroxyatrazine, and metolachlor in two soils from Virginia. J. Environ. Qual. 25:1179-1185.

Seybold, C., W. Mersie, and D. Delorem. 2001. Removal and degradation of atrazine and metolachlor by vegetative filter strips on clay loam soil. Commun. Soil Sci. Plant Anal. 32:723-737.

Thurman, E.M., D.A. Goolsby, D.S. Aga, M.L. Pomes, and M.T. Meyer. 1996. Occurrence of alachlor and its sulfonated metabolite in rivers and reservoirs of the Midwestern United States: The importance of sulfonation in the transport of chloroacetanilide herbicides. Environ. Sci. Technol. 30:569-574.

Tingle, C.H., D.R. Shaw, M. Boyette, and G.P. Murphy. 1998. Metolachlor and metribuzin losses in runoff as affected by width of vegetative filter strips. Weed Sci. 46:475-479.

Vellidis, G., R. Lowrance, P. Gay, and R.D. Wauchope. 2002. Herbicide transport in a restored riparian forest buffer system. Trans. ASAE 45:89-97.

Webster, E.P., and D.R. Shaw. 1996. Impact of vegetative filter strips on herbicide loss in runoff from soybean (Glycine max). Weed Sci. 44:662-671.

Wolfe, J.E., III, K.N. Potter, and D.H. Hoffman. 2000. A device for simulating overland flow. J. Soil Water Conserv. 55:102-104. 